ADALGISA GUGLIELMINO $(*)$ - MASSIMO OLMI $(* *)\left({ }^{\circ}\right)$ - STEFANO SPERANZA $(*)$

\title{
DESCRIPTION OF GONATOPUS XUI SP. N. FROM INDIA (HYMENOPTERA DRYINIDAE)
}

\author{
(*) Department of Agriculture and Forestry Sciences (DAFNE), University of Tuscia, Viterbo, Italy \\ (**) Via De Gasperi 10, Viterbo, Italy \\ $\left(^{\circ}\right.$ Corresponding author: olmimassimo@gmail.com
}

Guglielmino A., Olmi M., Speranza S. - Description of Gonatopus xui sp. n. from India (Hymenoptera Dryinidae).

A new species of Dryinidae (Hymenoptera: Chrysidoidea) is described from India: Gonatopus xui sp. n. It is the first species of Dryinidae reported from Himachal Pradesh. The new species belongs to group 7 of Gonatopus. The key to the females of the Oriental species of Gonatopus group 7 is modified to include the new taxon. The new species is named after the late Professor Zaifu Xu, from Guangzhou (China), well-known specialist of Chinese dryinids.

KeY Words: Gonatopodinae, Himachal Pradesh, Oriental region, taxonomy, keys.

\section{INTRODUCTION}

Dryinidae of the Oriental region were studied in recent years by XU et al. (2013). Their monograph was followed by supplements published by GUGLIELMINO \& OLMI (2013), KIM et al. (2013), OLMI et al. (2013, 2014, 2015a, 2015b, 2015c, 2016), Mita \& Pham (2014), Guglielmino et al. (2017), Mita et al. (2017).

In the Oriental region, the genus Gonatopus Ljungh, 1810, includes 59 species (XU et al., 2013; MiTA et al., 2017), among which 20 are reported from India. In 2017 the authors have examined a further new species of Gonatopus collected in India. It is described below.

\section{MATERIALS AND METHODS}

The description follows the terminology used by OLMI (1984) and XU et al. (2013). The measurements reported are relative, except for the total length (head to abdominal tip, without the antennae), which is expressed in millimeters. In the descriptions POL is the distance between the inner edges of the lateral ocelli; OL is the distance between the inner edges of a lateral ocellus and the median ocellus; OOL is the distance from the outer edge of a lateral ocellus to the compound eye.

The term "metapectal-propodeal complex" is here used in the sense of KAWADA et al. (2015). It corresponds to the term "metathorax + propodeum" sensu OLMI (1984) and XU et al. (2013).

The types of all Oriental species of Gonatopus were examined. The material studied in this paper is deposited in the following collections:

TAMU: Department of Entomology, Texas A. \& M. University, College Station, Texas, USA.

USNM: National Museum of Natural History, Washington, DC, USA.

\section{RESULTS}

Gonatopus xui sp. n.

(Fig. I, 1-2; Fig. II, 1)

\section{MATERIAL EXAMINED}

Holotype, 1 female: INDIA: Himachal Pradesh, Kothi Village and environs, IN-11, $32^{\circ} 18^{\prime} \mathrm{N} 77^{\circ} 11^{\prime} \mathrm{E}, 2300-2600$ m, 29.V-8.VI.1999, Yu. M. Marusik leg. [TAMU (to be transferred to USNM)].

\section{DESCRIPTION}

Apterous female; length $4.2 \mathrm{~mm}$. Head black, except mandible, clypeus, gena and anterior region of face testaceous; antenna brown, except antennomeres 1-2 testaceous; mesosoma black; metasoma brown; legs brown, except tarsi and part of trochanters testaceous. Antenna clavate; antennomeres in following proportions: 9:5:17:11:8:8:6:6:6:9. Head excavated, shiny, unsculptured; frontal line complete; occipital carina incomplete, only present behind ocellar triangle; $\mathrm{POL}=1 ; \mathrm{OL}=2 ; \mathrm{OOL}=9$. Palpal formula $5 / 3$. Pronotum crossed by strong transverse impression, with anterior collar and disc shiny, punctate, unsculptured among punctures. Scutum shiny, sculptured by many longitudinal striae, laterally with two pointed apophyses (Fig. I, 1). Scutellum shiny, smooth, flat. Mesopleuron shiny, unsculptured. Metanotum slightly hollow behind scutellum (Fig. I, 2). Metapectal-propodeal complex shiny, with disc and anterior surface unsculptured; posterior surface transversely striate. Metapleuron with anterior half unsculptured and posterior half transversely striate. Meso-metapleural suture very thin, slightly distinct and complete. Protarsomeres in following proportions: 16:3:5:18:26. Enlarged claw (Fig. II, 1) with one small subapical tooth and one row of five peglike setae, in addition to one bristle. Segment 5 of protarsus (Fig. II, 1) with one row of 20 lamellae; distal apex with about 10 lamellae. Tibial spurs 1/0/1.

Male: unknown.

DISTRIBUTION

Only known from the type locality (see above).

Hosts

Unknown.

\section{ETYMOLOGY}

The species is named after the late Prof. Zaifu Xu, specialist of Chinese dryinids and author, with Prof. Junhua He, of the monograph on Dryinidae of the Fauna Sinica (HE \& $\mathrm{Xu}, 2002)$.

\section{REMARKS}

The female of the new species is apterous, with pronotum crossed by a strong transverse furrow, the enlarged claw 


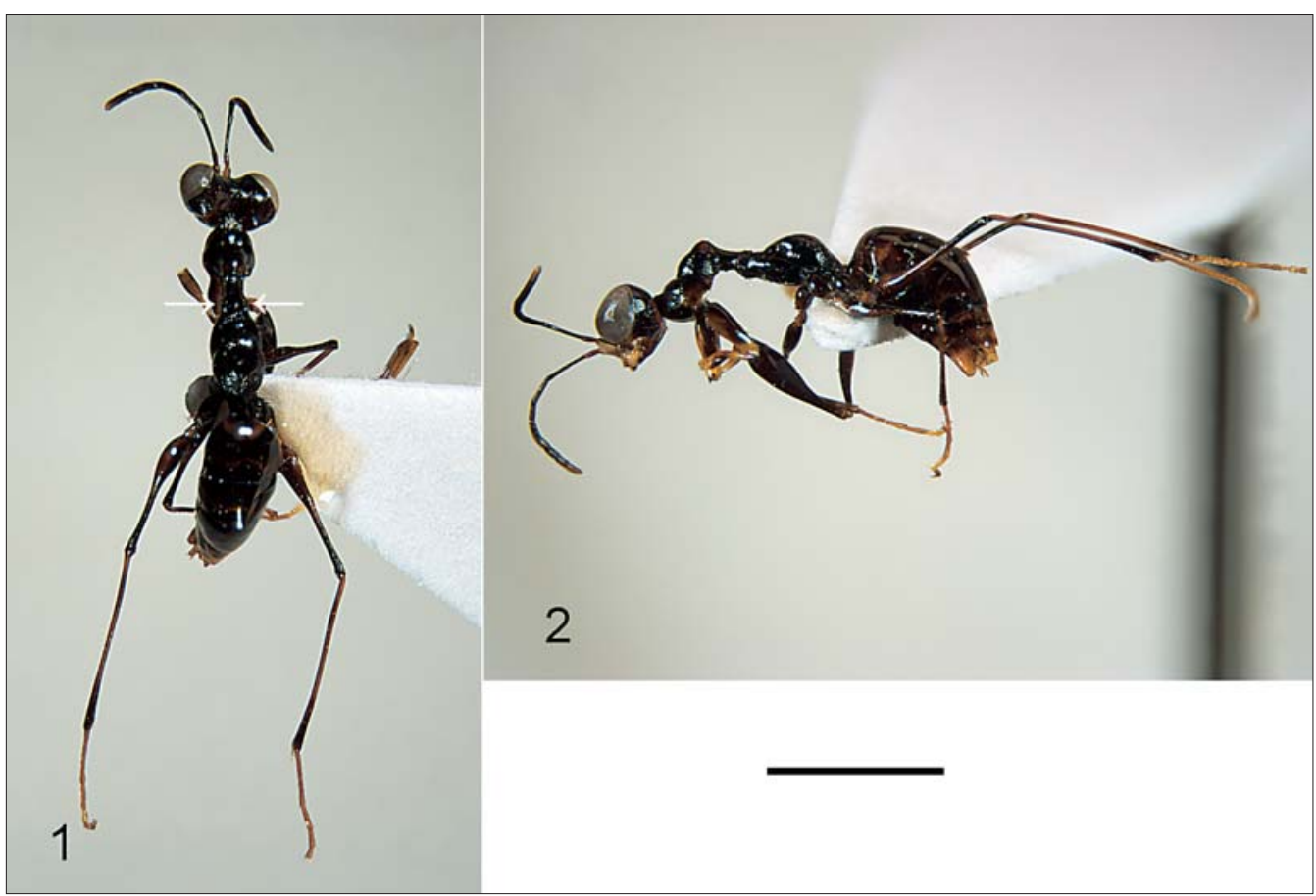

Fig. I-Gonatopus xui sp. n.: female holotype in dorsal (1) and lateral (2) view. Lateral apophyses of scutum indicated by arrows. Scale bar $1.83 \mathrm{~mm}$

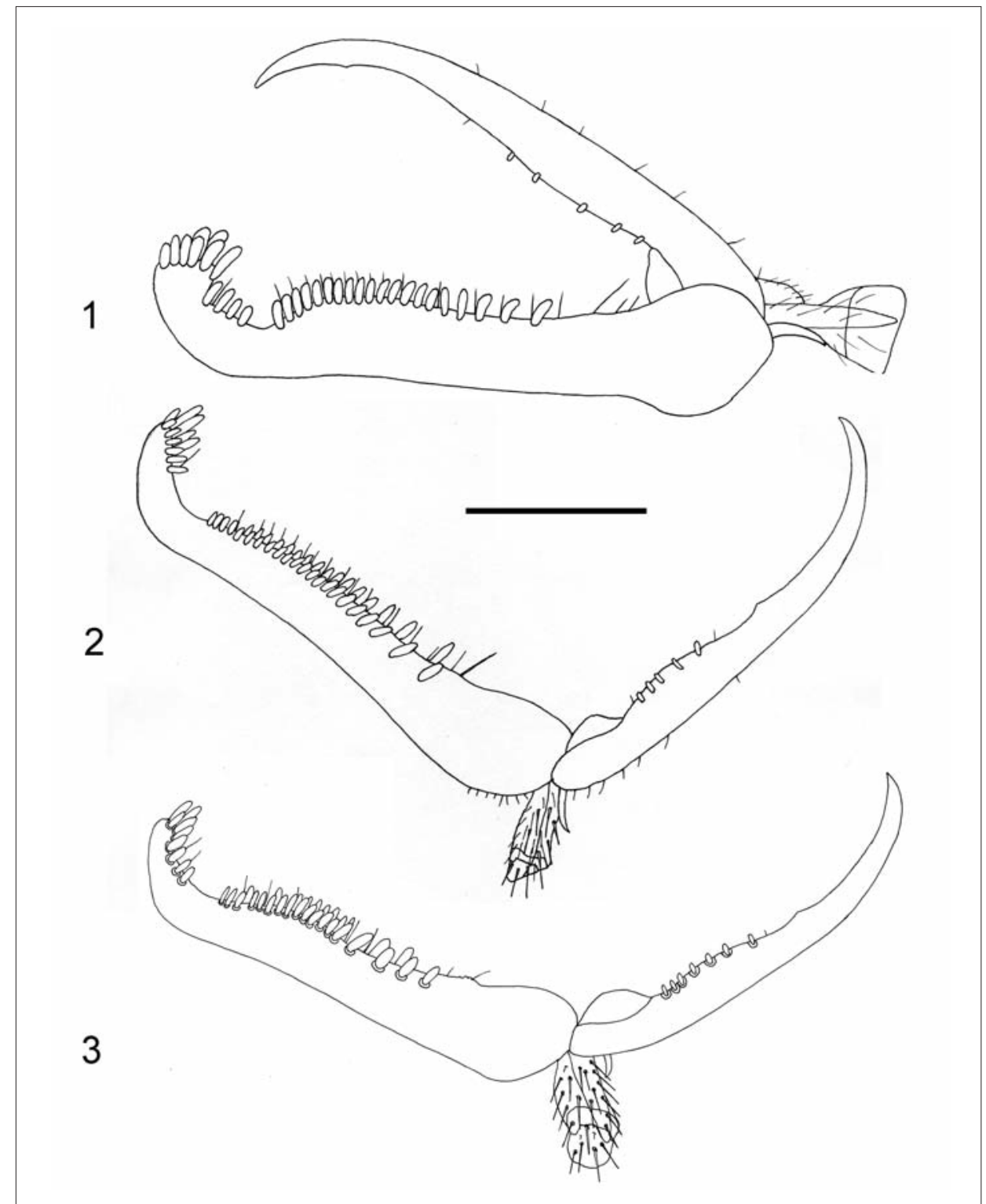

Fig. II - Chelae of holotypes of Gonatopus xui sp. n. (1), G. lankanus Olmi (2) and G. hainanensis Olmi (3). Scale bar $0.18 \mathrm{~mm}$ for $1,0.26 \mathrm{~mm}$ for $2,0.36 \mathrm{~mm}$ for 3 . 
provided of one small subapical tooth and the palpal formula 5/3. Because of these characters, G. xui belongs to group 7 of Gonatopus, according to the systematics proposed by XU et al. (2013). The new species can be included in the key to the females of the Oriental species of Gonatopus presented by XU et al. (2013) by replacing couplet 14 as follows:

14. Enlarged claw with subapical tooth situated nearer distal apex (Fig. II, 1) .......................................................... G. xui sp. n.

- Enlarged claw with subapical tooth farther from distal apex (Fig. II, 2-3)

14

14'. Head with face narrow and long [Fig. 128C in Xu et al. (2013)]; face and occiput sculptured by numerous parallel and longitudinal striae ................................................... lankanus Olmi

- Head with face shorter and more transverse (Fig. 127E in XU et al. (2013)); face and occiput slightly granulated, not sculptured by parallel and longitudinal striae G. hainanensis Olmi

\section{CONCLUSIONS}

Species of Gonatopus from India are known mainly thanks to the monograph on Dryinidae of the Oriental region by XU et al. (2013). The following 20 species were listed:

- Group 1: G. nearcticus (Fenton, 1927), known from Karnataka.

- Group 2: G. nigricans (Perkins, 1905): broadly spread in India and known from Bihar, Delhi, Orissa, Karnataka, Tamil Nadu and West Bengal; G. nudus (Perkins, 1912): known from Andhra Pradesh, Gujarat, Orissa and Tamil Nadu.

- Group 3: G. bengalensis Olmi, 1984: known from Assam; G. pyrillae (Mani, 1942): known from Punjab and Uttar Pradesh.

- Group 5: G. flavifemur (Esaki \& Hashimoto, 1932): known from Andhra Pradesh, Orissa and Tamil Nadu.

- Group 7: G. attenuatus Olmi, 1984: known from Karnataka, Kerala and Mysore; G. besucheti Olmi, 1991: known from Uttar Pradesh; G. daunus Olmi, 1984: known from Mysore; G. iarensis Olmi, 2005: known from Delhi, Karnataka and Tamil Nadu; G. javanus (Perkins, 1912): known from Karnataka and Delhi; $G$. lucidus (Rohwer, 1920): known from Bihar; $G$. mysorensis Olmi, 1984: known from Karnataka and Mysore; G. nivosus Olmi, 1984: known from Kashmir and Delhi; G. rufoniger Olmi, 1993: known from Karnataka; G. schenklingi Strand, 1913: known from Karnataka; G. superbus Olmi, 1987: known from Karnataka and Orissa; G. viraktamathi Olmi, 1987 : known from Karnataka; G. yasumatsui Olmi, 1984: known from Karnataka and Uttar Pradesh.

- Group 10: G. indicus (Olmi, 1987): known from Karnataka.

Following the above description of G. xui, the Gonatopus species known from India are now 21. G. xui is the first species of Dryinidae collected in Himachal Pradesh.

In Thailand, known Gonatopus species are 7 (Xu et al. 2013); in the Oriental region of China 24 (Xu et al., 2013); in Europe 50 (OlmI, 2013). The comparison with Europe shows that in general the knowledge of the Gonatopus species in all Asia and mainly in India is insufficient. Further research is necessary to fill the gap.

About the hosts, they are known only in ten of the 21 Gonatopus species recorded in India (GUGLIELMINo et al., 2013): another gap to be bridged.

\section{ACKNOWLEDGEMENTS}

Many thanks to Prof. James B. Woolley (Texas A. \& M. University, College Station, USA) for the loan of Gonatopus xui. The authors are very grateful to Prof. Maurizio Biondi (University of L'Aquila, Italy) for the multifocal pictures of the new species described in the present paper.

\section{REFERENCES}

Guglielmino A., Olmi M., 2013 - Description of Anteon seramense (Hymenoptera: Dryinidae): a new species from Indonesia. - Florida Entomol., 96 (2): 598-601.

Guglielmino A., Olmi M., BücKle C., 2013 - An updated host-parasite catalogue of world Dryinidae (Hymenoptera: Chrysidoidea). - Zootaxa, 3740: 1-113.

Guglielmino A., Olmi M., Marletta A., Xu, Z., 2017 Description of Aphelopus fuscoflavus, a new species of Dryinidae from Thailand (Hymenoptera, Chrysidoidea). - J. Hym. Res., 57: 115-121.

He J., Xu Z., 2002 - Hymenoptera Dryinidae. Fauna Sinica, 29, Science Press, Beijing, China, I-XII+464 pp.

KaWAda R, Lanes G.O., Azevedo C.O., 2015 - Evolution of metapostnotum in flat wasps (Hymenoptera, Bethylidae): implications for homology assessments in Chrysidoidea. - PLoS ONE, 10(10): e0140051.

Kim C.J., Olmi M., Lee S., Lim J., Choi G.W., Lee J.W., 2013 - A checklist of Dryinidae (Hymenoptera: Chrysidoidea) from Cambodia, with new records. - J. AsiaPacific Entomol., 16: 485-488.

Mita T., Nagano H., Olmi M., 2017 - Dryinidae and Embolemidae (Hymenoptera, Chrysidoidea) from Anijima, Ogasawara Islands, Japan. - Zootaxa, 4323 (2): 239-249.

Mita T., Pham H.T., 2014 - Dryinidae collected from Rice Paddy in Vietnam (Hymenoptera: Chrysidoidea). - Japan. J. Syst. Entomol., 20 (2): 245-246.

Olmi M., 1984 - A revision of the Dryinidae (Hymenoptera). - Mem. Amer. Entomol. Inst., 37: I-XII + 1913 pp.

Olmi M., 2013 - Fauna Europaea: Dryinidae. - In: Mitroiu M.D., 2013, Fauna Europaea: Hymenoptera. Fauna Europaea version 2017.10, https://fauna-eu.org (accessed 31 Jan 2018).

Olmi M., Xu Z., Guglielmino A., 2013 - First supplement to the monograph of the Oriental Dryinidae (Hymenoptera: Chrysidoidea): description of Neodryinus lohmani, a new species from Thailand. - Florida Entomol., 96 (4): 1556-1558.

Olmi M., Xu Z., Guglielmino A., 2014 -Descriptions of new fossil taxa of Dryinidae (Hymenoptera: Chrysidoidea) from Burmese amber (Myanmar). - Acta Entomol. Musei Nat. Pragae, 54 (2): 703-714.

Olmi M., Xu Z., Guglielmino A., 2015a - A new species of the genus Anteon Jurine (Hymenoptera, Dryinidae) from Thailand. - ZooKeys, 504: 141-147.

Olmi M., Xu Z., Guglielmino A., 2015b-Description of a new species of Deinodryinus (Hymenoptera: Dryinidae) from India. - Entomol. News, 125 (1): 33-37.

Olmi M., Xu Z., Guglielmino A., 2015c-Description of Dryinus laotianus (Hymenoptera: Dryinidae), a new species from Laos. - Florida Entomol., 98 (2): 560-562.

Olmi M., Xu Z., Guglielmino A., Speranza S., 2016-A new species of the genus Anteon Jurine (Hymenoptera, Dryinidae) from Laos. - ZooKeys, 561: 31-38.

Xu Z., Olmi M. \& He J., 2013 - Dryinidae of the Oriental region (Hymenoptera: Chrysidoidea). -Zootaxa, 3614, 1460. 
34 - Blank Page 